\title{
A Placental Conundrum: Exaggerated Placental Site Tumor
}

\author{
Sheetal Arora ${ }^{1}$, Sujata Raychaudhuri', Deepshikha Rana ${ }^{2 *}$ \\ ${ }^{1}$ Dept. of Pathology, VMMC and Safdarjung Hospital, New Delhi, India \\ ${ }^{2}$ Dept. of Pathology, ESIC Medical College, Faridabad, Haryana, India
}

\begin{abstract}
Exaggerated placental site (EPS) is defined as a non-neoplastic condition in which there is proliferation of number of implantation site intermediate trophoblastic cells that infiltrates the endometrium and myometrium. This is a benign lesion and it's an exaggeration of normal physiological process as the intermediate trophoblastic cells present in EPS are similar morphologically and immunophenotypically to those found in the normal implantation site. An exaggerated placental site may occur in association with normal pregnancy or an abortion. The significance of reporting this lesion lies in the fact that the cells of this lesion display an identical morphological features to the intermediate trophoblastic cells found in placental site trophoblastic tumour, placental site nodule \& epithelioid trophoblastic tumour. To confirm the morphological analysis, we used immunohistochemistry panel comprising of Cytokeratin 18, p63and ki-67(MIB-1). We here present a rare case of an exaggerated placental site in a 30-year-old female who was in her first trimester of pregnancy and presented with signs of incomplete abortion.
\end{abstract}

Keywords: Exaggerated Placental Site, Intermediate Trophoblast Cells, Myometrium

\section{Introduction}

Exaggerated placental site (EPS) is defined as a nonneoplastic condition in which there is proliferation of number of implantation site intermediate trophoblastic cells that infiltrates the endometrium and myometrium. This is a benign lesion and it's an exaggeration of normal physiological process as the intermediate trophoblastic cells present in EPS are similar morphologically and immunophenotypically to those found in the normal implantation site. It was previously named syncytial endometritis but due to its non-inflammatory, non-syncytial nature and its extention beyond endometrium, the World Health Organization renamed it Exaggerated placental site. (1) It is therefore must to uncover such lesions as it is difficult to distinguish it from other trophoblastic neoplastic lesions, which validates early diagnosis and better prognosis. EPS is a benign lesion but awareness of the constellation of its clinical, morphological and immunohistochemical features aids in establishing the correct diagnosis and distinguishing this neoplasm from other benign and borderline lesions of similar morphology but different treatment modalities.

\section{Case Report}

A 30-year-old female, 14 weeks pregnant, presented to gynaecology department with bleeding per vagina, lower abdominal pain along with high fever. On examination, her fever was $38^{\circ} \mathrm{C}\left(100.4^{\circ} \mathrm{F}\right)$, her pulse rate was increased and blood pressure was falling. Her haemoglobin was low and total leucocyte count was raised. She had a previous history of abortion. Emergency curettage was performed as there were signs of incomplete abortion which was sent for histopathology.

Microscopic examination showed intermediate trophoblastic cells along with variable number of multinucleated trophoblastic cells which infiltrated the endometrium and myometrium. Endometrial glands were surrounded by trophoblastic cells and the smooth muscles of myometrium was separated by nests, cords and individual implantation site trophoblastic cells. At places there was decidual reaction with evidence of necrosis and inflammation. Focal areas of hyalinisation were also noted. However, no chorionic villi/ increased mitotic activity was noted in the sections examined. (Figure 1,2,3)

It is difficult to distinguish it from placental site trophoblastic tumour(PSTT), placental site nodule(PSN)and epithelioid trophoblastic tumour(ETT) morphologically, hence immunohistochemical markers like CK 18, p63 and Ki67 proliferation index was done for this distinction. (TABLE:1) Our case shows CK 18 positivity, p63 negativity and proliferating index $<1 \%$ which confirmed our diagnosis of EPS.

CK 18 was done to confirm for the presence of intermediate trophoblastic cells. Once we know it is a trophoblastic lesion, it is important to differentiate between lesions of implantation site intermediate trophoblast and chorionic 
type intermediate trophoblast. For this, p63 is the marker of choice which is positive in lesions of chorionic type intermediate trophoblast and negative in implantation type. As p63 was negative, it excluded lesions of chorionic type like Placental site nodule(PSN) and Epithelioid trophoblastic tumour(ETT). Hence, the differential diagnosis was narrowed down to lesions of implantation site intermediate trophoblast (EPS \& PSTT) which are CK 18 positive and p63 negative. To differentiate between these two lesions, ki-67 was helpful. It is a proliferating index which is $<1 \%$ in EPS and $>8 \%$ in PSTT. In our case, it was $<1 \%$ which finally confirmed the diagnosis of EPS.

Table1: Immunohistochemistry Markers.

\begin{tabular}{|l|c|c|c|c|} 
IHC marker & $\begin{array}{c}\text { Exaggerated placental } \\
\text { site(EPS) }\end{array}$ & $\begin{array}{c}\text { Placental site nodule } \\
\text { (PSN) }\end{array}$ & $\begin{array}{c}\text { Placental site } \\
\text { trophoblastic tumor } \\
\text { (PSTT) }\end{array}$ & $\begin{array}{c}\text { Epithelioid trophoblastic } \\
\text { tumor (ETT) }\end{array}$ \\
\hline CK 18 & ++ & + & ++ & + \\
\hline p63 & - & $>50-75 \%$ & - & $<25 \%-75 \%$ \\
\hline Ki 67 & $<1 \%$ & $3-10 \%$ & $>10 \%$ & $>10 \%$ \\
\hline
\end{tabular}

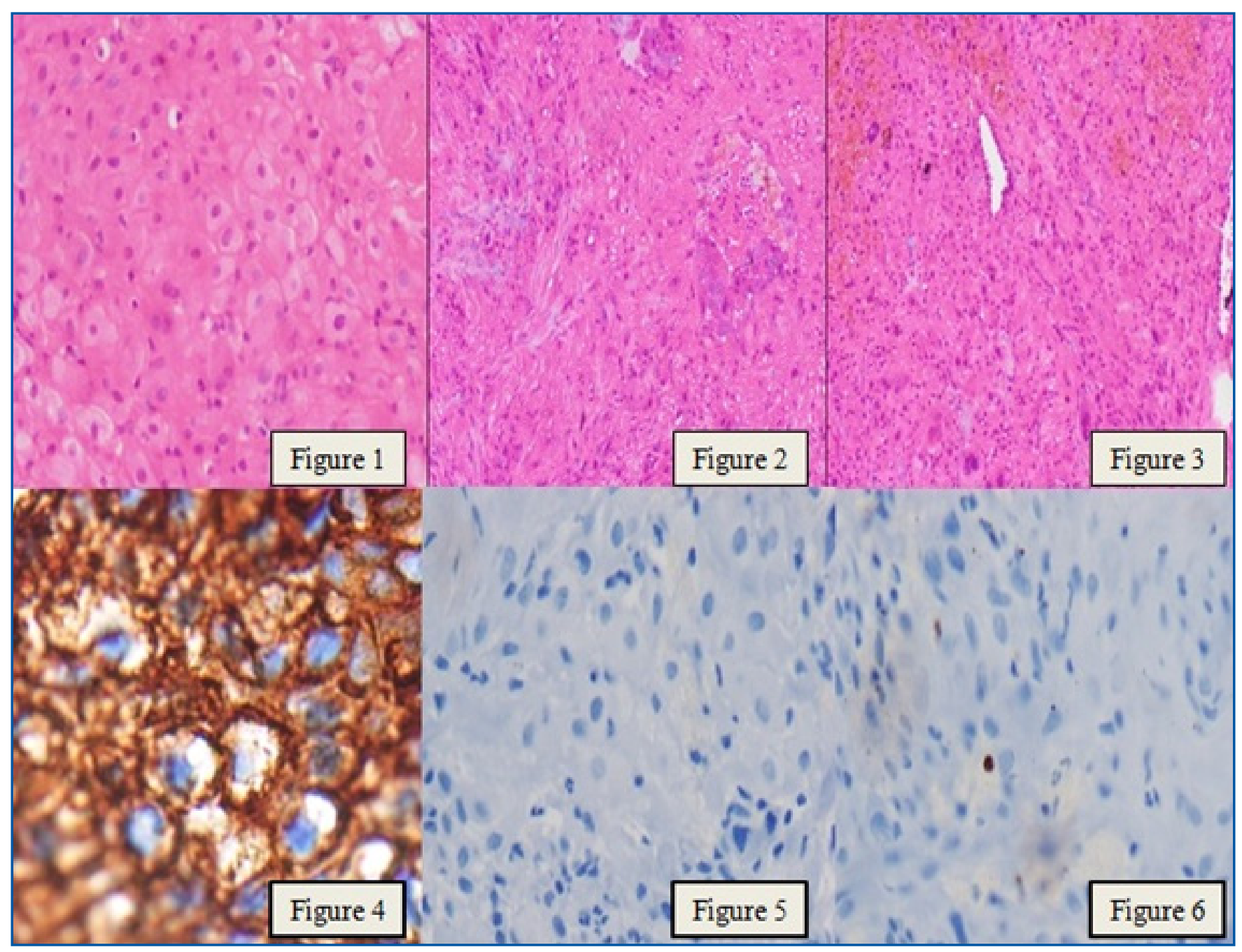

Fig. 1: Tissue section showing intermediate trophoblasts and decidualised cells. (H\&E, X400); Fig. 2: Tissue section showing intermediate trophoblastic cells infiltrating into myometrium. (H\&E, X100); Fig. 3: Tissue section showing intermediate trophoblastic cells infiltrating into endometrial gland. (H\&E,X100); Fig. 4: Tissue section showing intermediate trophoblastic cells showing CK 18 positivity. ; Fig. 5: Tissue section showing intermediate trophoblastic cells having negative staining for p63.; Fig. 6: Tissue section showing intermediate trophoblastic cells with Ki-67 proliferating index less than 1\%. 


\section{Discussion}

EPS is characterized by an exaggerated and increased infiltration of endometrium and myometrium by intermediate trophoblasts in the implantation area of the placenta. $(2,3,4)$ Intermediate trophoblasts provide foetalmaternal circulation during early pregnancy entering into spiral arteries in the basal layer. (5) So implantation site intermediate trophoblast is important for the maintenance of pregnancy. Infiltration of intermediate trophoblasts in the first trimester is only in the decidua, spiral arterioles and upper part of myometrium, physiologically and then regress gradually. So, when the intermediate trophoblastic cells infiltrate exaggeratedly into the myometrium or endometrium, failing to regress or involute the condition is called as an EPS. (5)

EPS is a lesion which frequently appears in normal pregnancy, ectopic pregnancy, abortion or molar pregnancy. $(1,6)$ We present a case of first trimester incomplete abortion.

These patients can have different clinical presentations like abdominal pain, high grade fever, vaginal bleeding and may or may not have previous similar histories. $(3,4)$ Our patient presented with features of incomplete abortion and we kept the differential diagnosis of placental-uterine pathologies.

EPS normal histology comprises of extensive infiltration of endometrium and myometrium by implantation site intermediate trophoblasts, some of them are multinucleated. Trophoblasts engulf the Endometrial glands and spiral arterioles. Smooth muscle cells of myometrium are separated by cords, nests and individual trophoblastic cells that diffusely infiltrate the myometrium. No areas of necrosis and mitoses are seen. Despite diffuse infiltration, these trophoblastic cells share similar morphological features of normal implantation site intermediate trophoblastic cells; these cells contain abundant eosinophilic cytoplasm with hyperchromatic and irregular nuclei. Chorionic villi are also seen which are morphologically unremarkable.

On histopathology in our case we observed, intermediate trophoblastic cells along with variable number of multinucleated trophoblastic cells infiltrating the endomyometrium along with areas of decidualisation. However, no chorionic villi and mitotic activity seen. The most commonly seen lesion with this histopathological picture and clinical profile is EPS. The importance lies in distinguishing this lesion from the other gestational diseases like PSN, PSST. EPS lacks mitotic activity, is composed of intermediate trophoblastic cells, multinucleated trophoblastic cells separated by masses of hyalinised stroma admixed with decidua and chorionic villi. PSTT on the other hand has a similar picture with mitotic figures. PSN can be differentiated on the basis of small size, circumscription, extensive eosinophilic extracellular matrix and paucity of mitotic figures. PSN are easily distinguished as they are microscopic lesions and much less cellular than the other two. $(6,7,8)$ However, final confirmation requires immunohistochemistry.

Cytokeratin 18 IHC was performed as Intermediate trophoblastic cells showsstrong positivity. (Figure 4) To differentiate between implantation site intermediate trophoblastic cells and chorionic type cells, we used p63 as a marker. We found p63 to be negative which indicated that intermediate cells are of implantation site. (Figure 5) Considering this we kept EPS and PSTT in our differential. It is important to make the differential diagnosis as the PSTT cells of the neoplastic proliferation of intermediate trophoblasts and the EPS cells have similar cytological and immunophenotypical features. Cases in which distinction is hard to make, Ki67 proliferation index is considerably useful. While Ki67 proliferation index being less than 1\% is in favour of EPS, levels more than 5\% support PSTT. Our Ki-67 index came out be less than 1\%. (Figure 6)

\section{Conclusion}

EPS is a benign trophoblastic lesion, having no risk of persistent gestational trophoblastic diseases. However, the awareness of this rare entity is paramount as it must be distinguished from other borderline and malignant lesions like PSTT, PSN and Choriocarcinoma which require different and aggressive treatment protocol unlike this lesion. There is utmost need for more literature and documentation of such cases to establish the criteria of diagnosing this lesion confidently on the basis of morphology alone. We would like to attract attention to EPS which is not frequently seen and it must be carefully ruled out with the help of its histopathological features followed by immunohistochemistry.

\section{References}

1. Ozdemir O, Sari ME, Selimova V, Ilgin BU, Atalay CR. 2014, 'A case report of complete mole with co-existent exaggerated placental site reaction and review of the literature', Niger Med J. 2014;55(2):2014, pp. 180-2.

2. Shih IM, Kurman RJ. The pathology of intermediate trophoblastic tumors and tumor-like lesions. Int J Gynecol Pathol. 2001;20(1):31-47. 
3. Sitolnicu S, Radulescu D, Gonzalez-Rocha T, Timar I, Puscasiu L, Nogales FF. Exaggereted plasental site lesion with unusual presentation in the cerviks of a perimenopasual patient. APMIS. 2008; 116:160-162.

4. Baergen RN, Rutgers JL. Trophoblastic lesions of the placental site. Gen Diagn Pathol. 1997;143(2-3):143-158.

5. Fisher SJ, Damsky CH. Human cytotrophoblast invasion. Semin Cell Biol. 1993;4(3):183-188.
6. Choi JJ, Emmadi R. Incidental placental site nodule in a fallopian tube. Int J Surg Pathol. 2014;22(1):90- 2.

7. Benischke K, Kaufmann P. In Trophoblastic neoplasms. Pathology of the human placenta 4th edition, Germany, Springer. 2000:754-767.

8. Jacob S, Mohapatra D. Placental site nodule: a tumorlike trophoblastic lesion. Indian J Pathol Microbiol. 2009;52(2):240-1

*Corresponding author:

Dr. Deepshikha Rana, MD (Pathology), Tutor,Dept. of Pathology, ESIC Medical College, Faridabad, Haryana

Phone: +9108527091742

Email: ranadeepshikha@yahoo.com

Financial or other Competing Interests: None. 